\title{
A brief introduction to the thematic series of neurorestoration in neurotrauma
}

This article was published in the following Dove Press journal: Journal of Neurorestoratology

\section{Shiqing Feng}

Department of Orthopedics, Tianjin Medical University General Hospital Tianjin, People's Republic of China
Correspondence: Shiqing Feng Department of Orthopedics, Tianjin Medical University General Hospital, Tianjin, People's Republic of China Tel +86 I39 20286292

Email sqfeng@tmu.edu.cn

\section{Introduction}

Neurotrauma is generally regarded as a public health problem that remains a leading cause of disabilities and death worldwide, and the costs to communities in terms of suffering and economics are enormous. Neurotrauma may be in the form of traumatic brain injury (TBI) or traumatic spinal cord injury (TSCI), or others, all of which are a heterogeneous group of pathologic disorders. The common causes of neurotrauma are road traffic accidents, falls and violence. Even current neurorestorative strategies, including cell therapy, neuromodulation and neurorestorative surgery, can restore patients with neurotrauma to some degree of neurological functions, ${ }^{1-6}$ there exists an urgent demand to find more effective methods for neurotrauma to better restore damaged or lost neurological functions and/or structures. The objective of this thematic series is to report the latest advances in neurotrauma to motivate clinicians and scientists to know more and find more effectively neurorestorative methods for neurotrauma. A brief summary of three papers in the thematic series is given in the following sections.

\section{Summaries of papers in thematic series Epidemiology of worldwide spinal cord injury $(\mathrm{SCl})$}

Kang et al searched the articles between January 1993 and June 2017 and reviewed the epidemiological indicators of SCI. The study showed that the incidence of SCI gradually increased with the expansion of human activities and motor vehicle accidents (MVAs) and falls gradually became the most common reasons for injury. Electrolyte disturbances, pulmonary infections, urinary tract infections (UTIs) and bedsores were the four most common complications. The results of the current study offered an epidemiological profile of SCI, and these data may provide with guidance in preventing complication, implementing preventive strategies and paying more attention to high-risk populations.

\section{Stem cell-based therapies to treat $\mathrm{SCl}$}

Shi et al provide a summary of recent advances regarding the stem cell-based therapies in the treatment of SCI and discussed future perspectives in this field. Currently, neurorestorative strategies, including stem cell therapy products or mature/functionally differentiated cell-derived cell therapy products, can restore patients with chronic complete SCI to some degree of neurological functions. However, the efficacy, safety 
and ethical concerns of stem cell-based therapy continue to be challenged. Nonetheless, stem cell-based therapies hold promise of widespread applications, particularly in areas of SCI, and have the potential to be novel therapeutics, which contributes to the repair of SCI.

\section{In vitro study of neural stem cells (NSCs) and activated Schwann cells (ASCs) cocultured in electrospinning polycaprolactone (PCL) scaffolds}

This study aims to investigate the biocompatibility of electrospinning PCL fiber scaffolds and coculture system, which consisted of NSCs and ASCs. The results showed that the average diameter of fibers in electrospinning PCL scaffolds was about $7.93 \pm 1.41 \mu \mathrm{m}$, and ASCs could grow well at the density of $2 \times 10^{4} / \mathrm{cm}^{2}$, and a certain number of ASCs distributed along with the longitudinal axis of fibers. Cell Counting Kit-8 (CCK-8) experiment showed that ASCs as well as NSCs could proliferate gradually in the PCL scaffold, and NSCs differentiated into astrocytes, neurons and oligodendrocytes in the PCL scaffold; PCL scaffolds could improve the differentiation rate of neurons. After NSCs and ASCs were cocultured on electrospinning PCL scaffolds, NSCs and ASCs could form three-dimensional (3D) cultured system in PCL scaffolds, and NSCs can differentiate into neurons distributed around the ASCs that produce myelin basic protein. Thus, electrospinning PCL fibrous scaffolds formed a 3D system and showed good biocompatibility, and the fibers had the induced effect on the distribution of ASCs.

\section{Perspectives}

Currently, the cell therapy can partially restore neurological functions and/or structures by paracrine and direct repair through the mechanisms of cell replacement, neuroprotection, neuromodulation or neurostimulation, neuroplasticity, immunomodulation, axonal regeneration and sprouting, remyelination or neurorepair, neuroregeneration or neurogenesis after neurotrauma. ${ }^{7,8}$ Traumatic injuries such as brain injury and SCI still are reasons which severely affect the patients' physical and/or cognitive abilities. Therefore, neurotrauma in the central nervous system is a big challenge for further restoring neurological functions due to the presence of many molecules inhibitory or poor intrinsic microenvironment after neurorestoration.

Through incredible advancements in medical technology, the promise of personalized, precision medicine provides a new direction for neurorestoration after neurotrauma. In recent years, some innovative technologies have been brought, which include biomarker detection, more sensitive magnetic resonance imaging, monitoring perfusion pressure of spinal cord, monitoring blood flow of spinal cord, spinal gray matter test and genetic test. Therefore, these innovative technologies will create more neurorestorative therapeutic or researching methods which may have better neurorestorative effect for neurotrauma.

\section{Disclosure}

The author reports no conflicts of interest in this work.

\section{References}

1. Huang H, Sun T, Chen L, et al. Consensus of clinical neurorestorative progress in patients with complete chronic spinal cord injury. Cell Transplant. 2014;23(Suppl 1):S5-S17.

2. Huang H, Xi H, Chen L, Zhang F, Liu Y. Long-term outcome of olfactory ensheathing cell therapy for patients with complete chronic spinal cord injury. Cell Transplant. 2012;21(Suppl 1):S23-S31.

3. Grecco LH, Li S, Michel S, et al. Transcutaneous spinal stimulation as a therapeutic strategy for spinal cord injury: state of the art. $J$ Neurorestoratol. 2015;3:73-82.

4. Jacques L, Safaee M. Epidural spinal cord stimulation for recovery from spinal cord injury: its place in therapy. J Neurorestoratol. 2016;4:63-67.

5. Huang H, Chen L, Huang H. Clinical neurorestorative progress in traumatic brain injury. $J$ Neurorestoratol. 2015;3:57-62.

6. Huang H, Mao G, Feng S, Chen L. 2016 Yearbook of neurorestoratology. J Neurorestoratol. 2017;5:111-115.

7. Huang H, Mao G, Chen L, Liu A. Progress and challenges with clinical cell therapy in neurorestoratology. J Neurorestoratol. 2015;3:91-95.

8. Huang H, Chen L. Neurorestorative process, law, and mechanisms. J Neurorestoratol. 2015;3:23-30.

Dove Medical Press encourages responsible, free and frank academic debate. The content of the Journal of Neurorestoratology 'Editorial' section does not necessarily represent the views of
Dove Medical Press, its officers, agents, employees, related entities or the Journal of Neurorestoratology editors. While all reasonable steps have been taken to confirm the content of each Editorial, Dove Medical Press accepts no liability in respect of the content of any Editorial, nor is it responsible for the content and accuracy of any Editorial.

Journal of Neurorestoratology

Dovepress

\section{Publish your work in this journal}

The Journal of Neurorestoratology is an international, peer-reviewed, open access online journal publishing original research and review articles on the subject of Neurorestoratology. To provide complete coverage of this revolutionary field the Journal of Neurorestoratology will report on relevant experimental research, technological advances, and clinical achievements. The manuscript management system is completely online and includes a very quick and fair peer-review system, which is all easy to use. Visit http://www.dovepress.com/testimonials. php to read real quotes from published authors. 